\title{
Tritiated Water Interaction with Stainless Steel
}

Glen R. Longhurst

May 2007

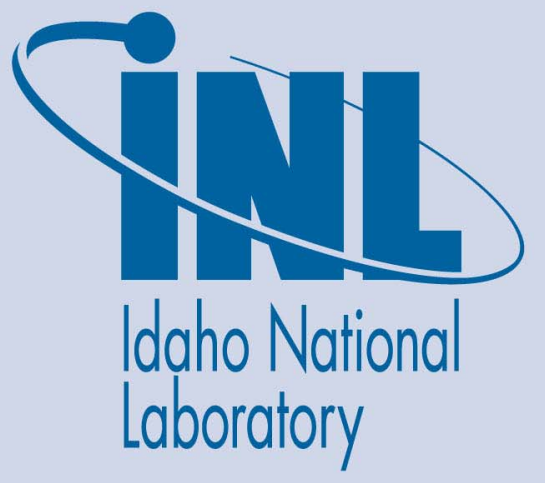

The INL is a U.S. Department of Energy National Laboratory operated by Battelle Energy Alliance 


\title{
Tritiated Water Interaction with Stainless Steel
}

\author{
Glen R. Longhurst
}

May 2007

\section{Idaho National Laboratory \\ Idaho Falls, Idaho 83415}

Prepared for the

U.S. Department of Energy

Office of Nuclear Energy

Under DOE Idaho Operations Office

Contract DE-AC07-05ID14517 


\title{
Tritiated Water Interaction with Stainless Steel
}

\author{
INL/EXT-07-12587
}

April 2007

Approved by:

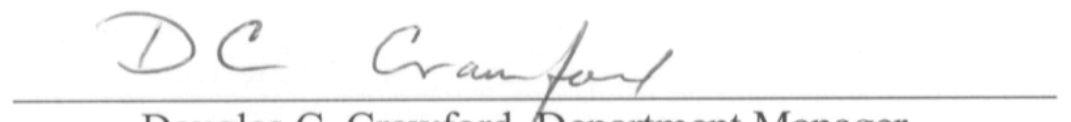

Douglas C. Crawford,Department Manager

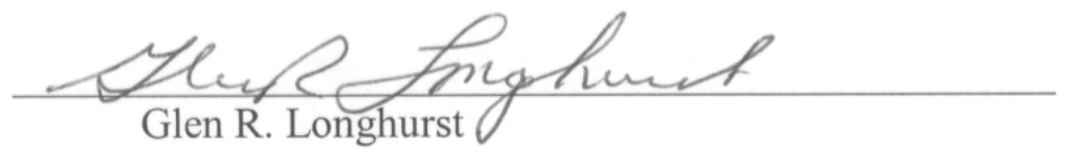

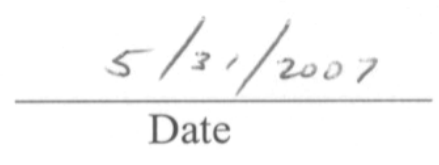

$\frac{6 / 15 / 2007}{\text { Date }}$ 


\section{ABSTRACT}

Experiments conducted to study tritium permeation of stainless steel at ambient and elevated temperatures revealed that HT converts relatively quickly to HTO. Further, the HTO partial pressure contributes essentially equally with elemental tritium gas in driving permeation through the stainless steel. Such permeation appears to be due to dissociation of the water molecule on the hot stainless steel surface. There is an equilibrium concentration of HTO vapor above adsorbed gas on the walls of the experimental apparatus evident from freezing transients. The uptake process of tritium from the carrier gas involves both surface adsorption and isotopic exchange with surface bound water. 


\section{CONTENTS}

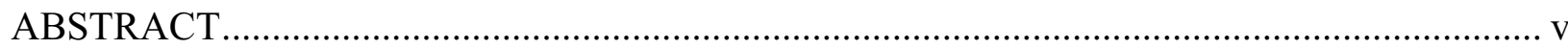

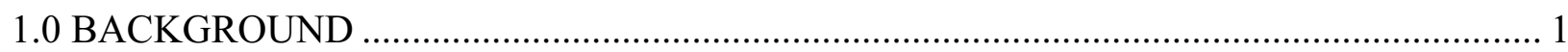

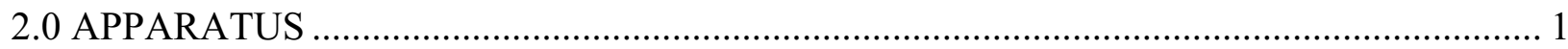

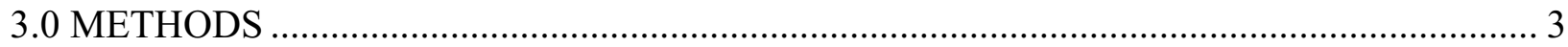

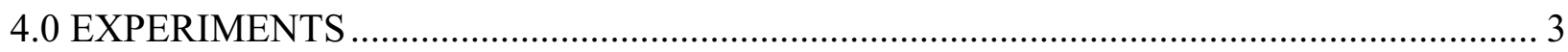

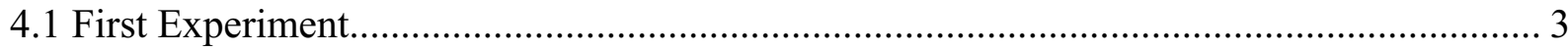

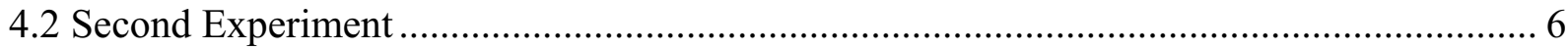

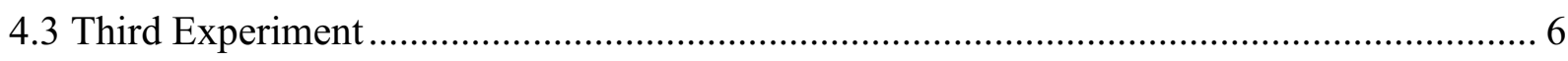

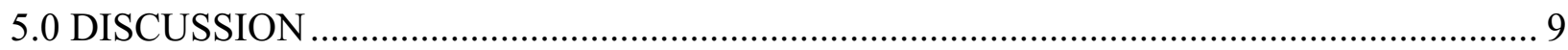

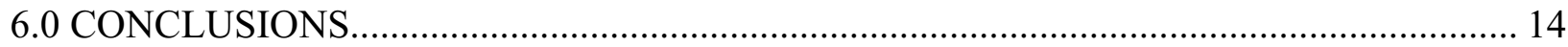

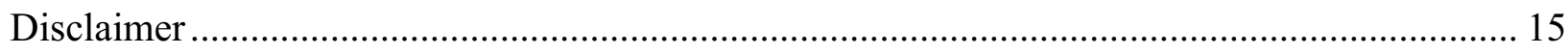

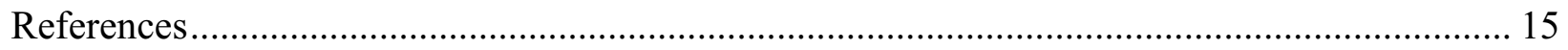

\section{FIGURES}

Figure 1. Experimental apparatus used in permeation experiments. .......................................2

Figure 2. Experiment showing conversion of HT to HTO and its adsorption on system

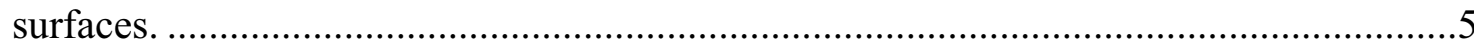

Figure 3. Second experiment showing clearly the conversion of HT to HTO in the inner loop and the effect of HTO vapor pressure on tritium permeation...............................

Figure 5. Tritium fraction removed from the experiment of Figure 2 .................................

Figure 6. Arrhenius plot of slopes of oxidation rates in Figure 5.........................................10

Figure 7. Variation of water adsorption time constant with amount adsorbed...........................14 


\subsection{BACKGROUND}

Early in the history of the Fusion Safety Program at what was then the Idaho National Engineering Laboratory (now Idaho National Laboratory), experiments were performed to gain basic experience and familiarity with tritium interactions with various structural materials anticipated for use in fusion reactors. One of those was Type 304 stainless steel. The expectation was that inventories of tritium in the structures of a fusion machine could be released in the event of an accident or other off-normal operating condition. There was a need to become familiar with such processes as solution, permeation, trapping, and adsorption of tritium and its most likely molecular manifestations with these structural materials.

One of the first experiments performed was simple permeation through a heated column. The objective was to introduce tritium as HT in research grade He with about 400 appm $\mathrm{H}_{2}$ to the inside of a heated tube and observe its permeation by passing a sweep gas from the downstream side through an ion chamber.

\subsection{APPARATUS}

Figure 1 shows a schematic of the experimental apparatus used in these experiments. The key item is the permeation column shown at the right edge of the figure. The column consisted of an inner chamber, which supported re-entrant flow of tritiated gas. The permeation wall was made of $1 / 2$-inch 304 stainless steel tubing, approximately $30 \mathrm{~cm}$ long with $0.89-\mathrm{mm}(0.035$-inch) wall thickness. The inlet and outlet tubes were standard 1/4-inch stainless steel tubing as was all other system ducting. The outer chamber of the column was also type 304 stainless, 1 -inch diameter, with $1.02-\mathrm{mm}(0.040$-inch) walls. Ends were closed with 1.59-mm (1/16-inch) thick type 304 stainless steel plate. The column was spiral wrapped with a nominally $1-\mathrm{m}$ long, 500-W coaxial heating rod. Temperature control was maintained with a PID temperature controller using a standard Type-K thermocouple attached to the column at mid height. The column was wrapped with ceramic wool insulation. Other loop ducts were wrapped with heater tape and then with insulation for baking out the tubes and other structures.

Using gas expansion techniques with a calibrated external volume, the volume of the inner loop was found to be $2.824 \mathrm{~L}$ while the volume of the outer loop was $3.745 \mathrm{~L}$. The volume of external duct work not directly part of either inner or outer loops was $0.156 \mathrm{~L}$. The approximate surface area of the inner loop was $0.77 \mathrm{~m}^{2}$ and the surface area of the outer loop was approximately $1.5 \mathrm{~m}^{2}$. Of those areas, the heated zone for the inner loop had an area of about $155 \mathrm{~cm}^{2}$. The area of the heated zone in the outer loop was about $460 \mathrm{~cm}^{2}$.

The ${ }^{4} \mathrm{He}$ supply bottle was a standard A1 bottle of research grade He with a 2-stage pressure regulator. HT (3.4 $\mathrm{mCi} / \mathrm{mole})$ and about $400 \mathrm{ppm} \mathrm{H}_{2}$ in otherwise pure ${ }^{4} \mathrm{He}$ was furnished in a nominally 2.7 -L lecture bottle, also with a 2 -stage pressure regulator.

Ion chambers were acquired from Mound Laboratory and were essentially identical to ones later marketed under the Femto-tech brand name. The chamber volumes on these ion chambers were $2 \mathrm{~L}$ each with wire grid electrodes. There were no compensation chambers. 


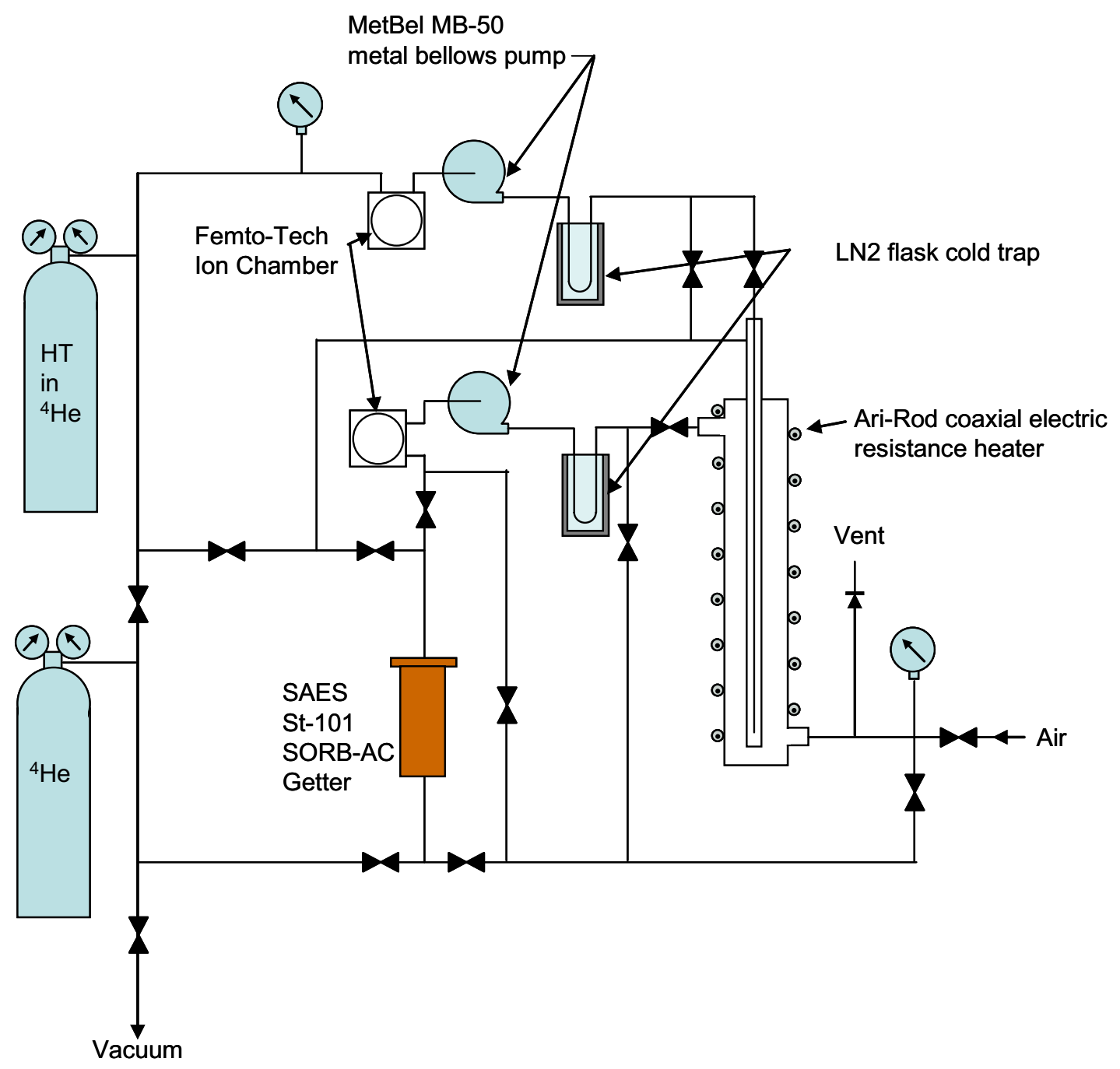

Figure 1. Experimental apparatus used in permeation experiments.

Circulation of gas in the two loops was accomplished using MetBel MB-21 metal bellows pumps. These had a nominal pumping rate of $4.25 \mathrm{~L} / \mathrm{min}(0.15 \mathrm{scfm})$. That gave an inner loop mixing time constant of about 40 seconds while the mixing time constant for the outer loop was about 53 seconds.

Each loop was furnished with a cryogenic trap made locally by spirally wrapping approximately $1 \mathrm{~m}$ of $1 / 4$-inch stainless steel tubing at a 2.54 -cm (1-in) radius and locating it in an open-topped $\mathrm{LN}_{2}$ dewar that could be filled and applied to or removed from the coil.

Pressure gauges used were standard Borden tube gauges with ranges of $-1.01 \mathrm{E}+05 \mathrm{~Pa}(-29.9$ inches of $\mathrm{Hg}$ ) to $689 \mathrm{kPa}(100 \mathrm{psig})$ relative to atmospheric. Operation was typically at or very near atmospheric pressure inside the system, and, except for volume determinations, high precision pressure measurements were not necessary on these experiments. The volumes were measured using an MKS Baratron capacitance manometer with a full-scale range of $1 \mathrm{bar}$. 
Disposition of tritium was accomplished on a SAES SORB-AC getter cartridge, which made use of SAES St-101 getter material. This was subsequently disposed of as ordinary radioactive waste.

Valves used were manual bellows-seal valves with polyimide valve stem tips. The exceptions were two check valves set for $138 \mathrm{kPa}(20 \mathrm{psig})$ opening, used as a safety precaution in case of overpressure in the inner and outer loops from runaway heating.

Vacuum was provided using a 50-L/min Pfeifer-Balzers TPH-50 turbomolecular pump backed by a standard oil-sealed rotary vane pump. An ion gauge in the pump inlet duct provided vacuum pressure readings.

The entire system was set up in a standard Class-A chemical fume hood with the vacuum pumping system installed below the working floor of the hood.

\subsection{METHODS}

A typical experiment consisted of applying vacuum to the entire system with the heater tapes on for a period of 12 to 20 hours. With heater tapes off and the system cool, pure He was admitted to the entire system to a pressure about $50 \mathrm{~mm} \mathrm{Hg}$ below local atmospheric. The inner loop was then isolated from the outer loop and from the column while the remainder was filled to full atmospheric pressure, again with pure He. Tritium bearing gas was then admitted to the inner loop from the lecture bottle slowly, with the circulation pump on but isolated from the permeation column, until the desired activity was obtained in the inner loop. This was typically 20 to $50 \mathrm{mCi} / \mathrm{m}^{3}$.

In some experiments, the column would then be heated to $500^{\circ} \mathrm{C}$, which took only about 5 minutes. In other experiments, heating came later. Circulating pumps pushed gases around the circuits of the inner and outer loops. Then the experiment would begin by redirecting flow in the inner loop through the column and recording ion chamber readings on a 2-channel strip chart recorder. Figures presented hereafter are digital tracings of scanned images of those strip charts.

At intervals, $\mathrm{LN}_{2}$ was added to one of the cold traps or the other as a means of identifying the HTO fraction in the gas in that loop. In reality there would be $\mathrm{H}_{2} \mathrm{O}$ and a small quantity of $\mathrm{T}_{2} \mathrm{O}$, but HTO was by far the dominant tritiated water form, just as HT was the dominant elemental tritiated gas species.

\subsection{EXPERIMENTS}

Three experiments are presented here. The first and second show particularly well the conversion of HT to HTO, both in the cold system duct work and then in the permeation column. The second and third illustrate how HTO partial pressure contributes to the tritium permeation in the system.

\subsection{First Experiment}

The data from the first experiment are shown in Figure 2. Tritium, as HT in He, was admitted to the inner loop at an elapsed time between 8 and 25 minutes. Initial tritium activity in the inner 
loop was $22.5 \mathrm{mCi} / \mathrm{m}^{3}$. $\mathrm{LN}_{2}$ applied at 26 minutes, as the tritium activity was reaching its peak, showed that the conversion to HTO had begun almost immediately, or that some of the tritium came in as HTO. Three percent had been converted after only about 20 minutes of exposure to the cold inner system not including the permeation column. Within two minutes of removing the cryogen from the inner loop cold trap (sudden rise in activity at about 30 minutes), the gas was admitted to the permeation column. The volume expansion resulted in the abrupt tritium activity drop of $3 \%$.

Over the next half hour, the tritium activity in the gas dropped to about $95 \%$ of its initial level, then it remained nearly constant until the column was heated. During that time, the quantity of non-condensable (HT) tritium appears to have remained nearly constant. $\mathrm{LN}_{2}$ was again added to the cold trap for two periods of several minutes before heating began, revealing a relatively constant HT fraction in the gas of about $85 \%$ of the initial tritium activity after that half hour. Because the temperature of all the exposed surfaces was low, the loss in overall tritium level ( $\mathrm{LN}_{2}$ off) must be attributed to surface adsorption, probably of water molecules [1]. However, some tritium could undergo isotopic exchange with water or $\mathrm{OH}$ radicals bound to the surface [2]. Thus, in the initially cold (ambient temperature) system, approximately $17 \%$ of the HT was converted to HTO or OT, and of that, about a third was adsorbed on the walls.

At 150 minutes into the experiment, the permeation column was heated to $500^{\circ} \mathrm{C}$. Almost immediately, the fraction of water increased and the overall tritium activity in the inner loop began to fall linearly. When the temperature was increased to $600^{\circ} \mathrm{C}$ at 190 minutes, the rate of loss increased. Examination of the tritium activity in the outer loop shows it began to rise when the permeation column was heated. Its rate of climb increased with the change to $600^{\circ} \mathrm{C}$, falling back to the original rate when the temperature went back to $500^{\circ} \mathrm{C}$. During all this time, tritium activity in the outer loop rose monotonically, increasing faster at the higher column temperature. and then returning to the previous rate when the temperature returned to $500^{\circ} \mathrm{C}$. The tritium that permeated to the outer loop was more than half water, as the cold-trap-on activity levels reveal.

By 300 minutes, nearly $90 \%$ of the tritium in both loops had been converted to water. The activity of tritium in the inner loop had fallen to only half of its original level. Most of that tritium had not permeated to the outer loop. Likewise, on solubility grounds, the loss from the inner loop gas phase cannot be explained by uptake in the heated column. Therefore, it must be concluded that with the added water vapor pressure, more was deposited on system walls. This is also evidenced by the spikes in tritium activity when the $\mathrm{LN}_{2}$ was removed from the cold trap. While there, the cryogen reduced that vapor pressure, drawing the HTO from the surfaces where it was adsorbed. When thawed, the water (HTO) was initially above its equilibrium value, and it got pushed back onto the surfaces with a time constant of about three minutes. This is much longer than the pump mixing transient of only 40 seconds, so it is not just a vapor spike in the ion chamber. At 310 minutes, the slight drop in inner loop tritium activity was the result of connecting an additional loop segment, expanding the inner loop volume, in preparation for evacuation, which occurred at 320 minutes. 


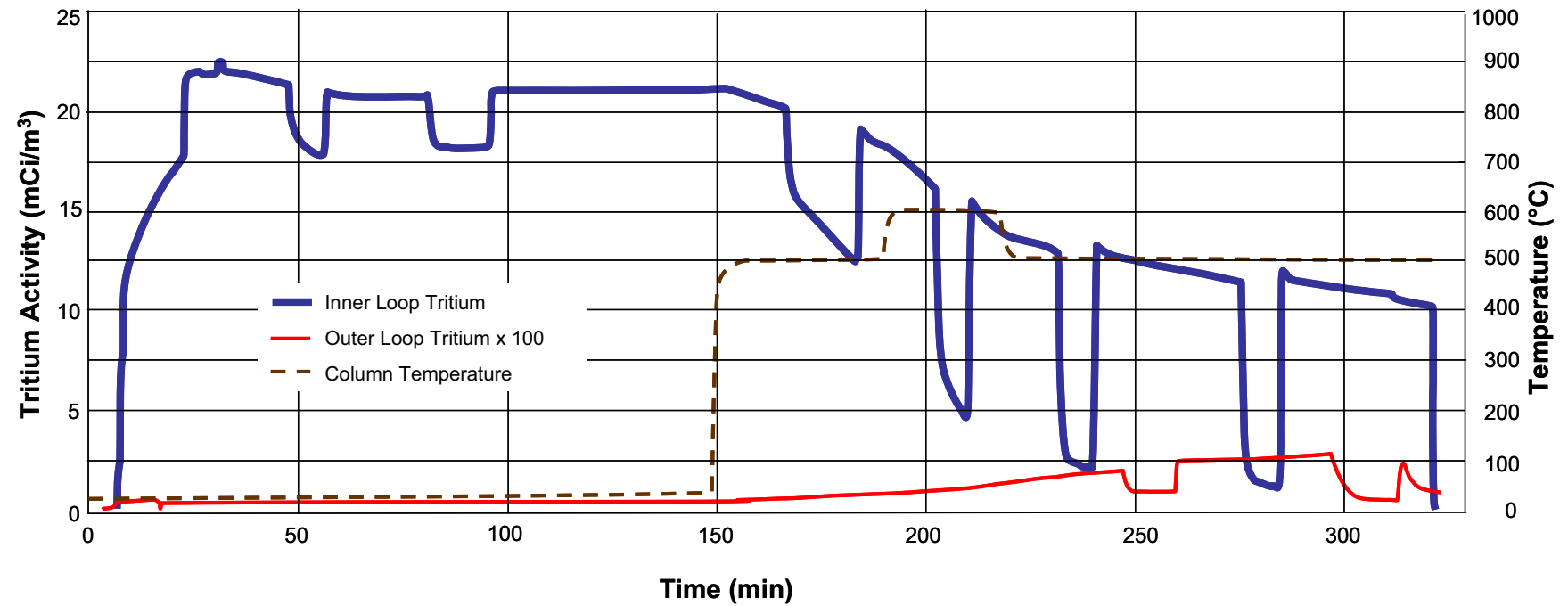

Figure 2. Experiment showing conversion of HT to HTO and its adsorption on system surfaces. 


\subsection{Second Experiment}

Figure 3 shows tritium activity levels for the second experiment in this series. This time, the permeation column was heated before the admission of tritium to the inner loop, but the remainder of the system was cold. Tritium introduction took place at about 8 minutes, and it was discovered that inner and outer loops had been inadvertently left connected after a previous outgasing of the entire system. The outer loop was immediately isolated and the gas in it passed through the getter bed to reduce the tritium level in that loop to a low background level.

At about 35 minutes into the experiment, $\mathrm{LN}_{2}$ was applied to the cold trap of the inner loop. Once again, it was observed that about $5 \%$ of the tritium had already been converted to water.

At 45 minutes into the test, with the $\mathrm{LN}_{2}$ still applied to the inner loop, the tritium was admitted to the permeation column. Immediately, the tritium level began to fall as tritium contacted the hot stainless steel surface of the permeation column and reacted with oxides and/or hydroxides there to produce water. The time constant for that decline in activity was 70 minutes. At 150 minutes, when the $\mathrm{LN}_{2}$ was removed, about $3 / 4$ of the tritium in the system had been converted to water, and about a third of that water had been adsorbed on system walls. The spike in inner-loop ion chamber tritium activity at 150 minutes is a mixing transient in the ion chamber. This comes about as gas rich in melted and subsequently evaporated water from the cold trap enters the ion chamber. The HTO in the ion chamber then becomes diluted as water in the cold trap completes evaporation and drier gas comes into the ion chamber and mixes with it. Notice that the loss rate of tritium in the inner loop accelerated when the column temperature was increased to $600^{\circ} \mathrm{C}$. The tritium permeation rate into the outer loop also increased when the temperature was increased, though permeation cannot account for the rate of loss in the inner loop.

A most interesting feature of this test was that when $\mathrm{LN}_{2}$ was added to the inner loop cold trap at about 208 minutes, notwithstanding the column was hot, the permeation rate fell in proportion to the total tritium activity removed from the gas by the cryogenic trap. When the cryogen was removed and the HTO returned to the gas, the permeation rate resumed at its former rate. When the column was cooled back to $500^{\circ} \mathrm{C}$, the permeation rate declined.

Once again, about $3 / 4$ of the tritium in the outer loop existed as HTO, as evidenced by the cold trap results shown between 240 and 253 minutes. It is not known how much of the tritium that permeated to the outer loop and was converted to water was adsorbed on the walls of the outer loop. Based on results from the inner loop, it may have been a third of the permeating tritium.

\subsection{Third Experiment}

Figure 4 shows results from an experiment that was conducted the following day, after the inner an outer loops had been charged, the inner one with $20 \mathrm{mCi} / \mathrm{m}^{3}$ of $\mathrm{HT}$ and the $\mathrm{He}-\mathrm{H}_{2} \mathrm{mix}$, and 


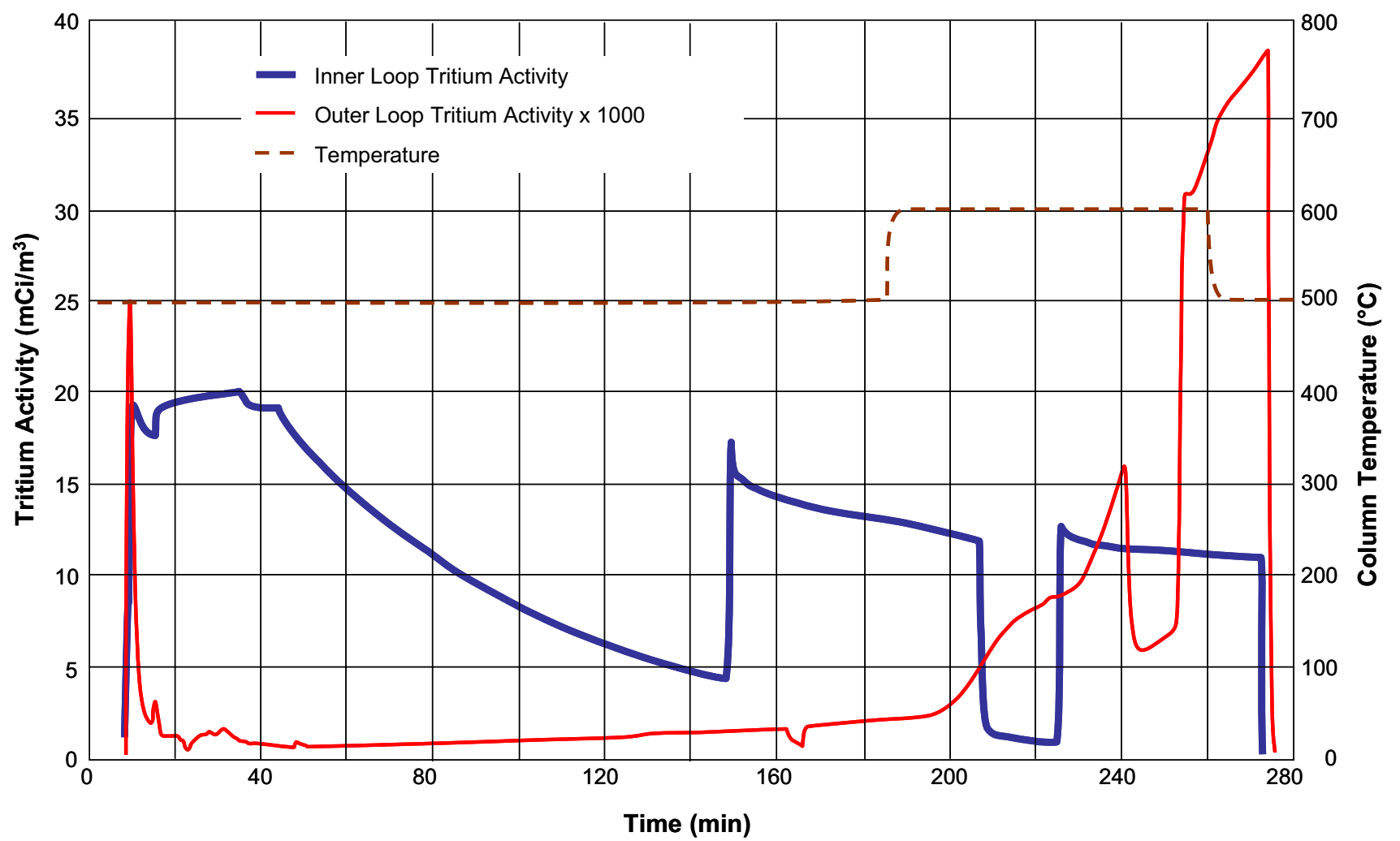

Figure 3. Second experiment showing clearly the conversion of HT to HTO in the inner loop and the effect of HTO vapor pressure on tritium permeation. 


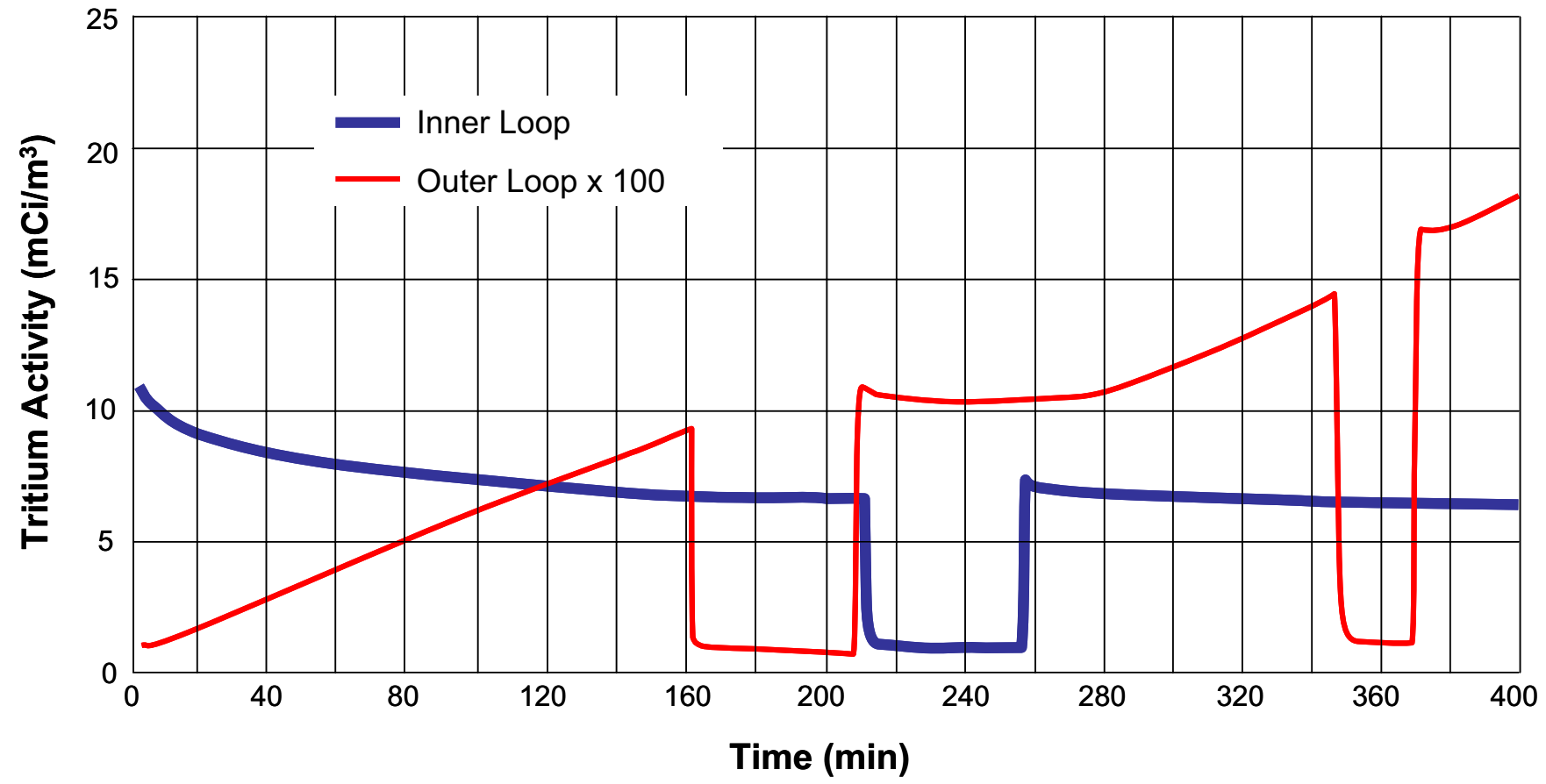

Figure 4. Followup experiment at $500^{\circ} \mathrm{C}$ showing that $\mathrm{HTO}$ partial pressure drives permeation. 
the outer one with only the $\mathrm{He}-\mathrm{H}_{2}$ mix, both with total pressures at atmospheric. The loops were allowed to equilibrate overnight without admitting tritium to the permeation column, which was held at $500^{\circ} \mathrm{C}$ for the entire experiment. The inner loop was then connected to the column. Again $\mathrm{LN}_{2}$ was applied to the cold traps at various periods during the transients.

\subsection{DISCUSSION}

Consider first the conversion of HT to HTO. It is interesting in the first experiment (Figure 2) that the conversion rate accelerated substantially when the gas was admitted to the cold permeation column even though the surface-to-volume ratio decreased. One reason for this may be that the column had previously been exposed to air while the surface was hot, thereby assumedly changing the nature of its surface and possibly acquiring a much richer inventory of $\mathrm{O}$ to participate in oxidation reactions.

The experiment of Figure 2 may be examined to determine the rate of conversion to water. In Figure 5 are shown (symbols) the natural logarithms of the ratios of initial tritium in the experiment to that remaining after uptake by the walls of the inner loop. Also shown there is the temperature history of the permeation column where most of the conversion activity is believed to take place. The data points appear to be linear with different slopes within the time periods associated with different temperatures.

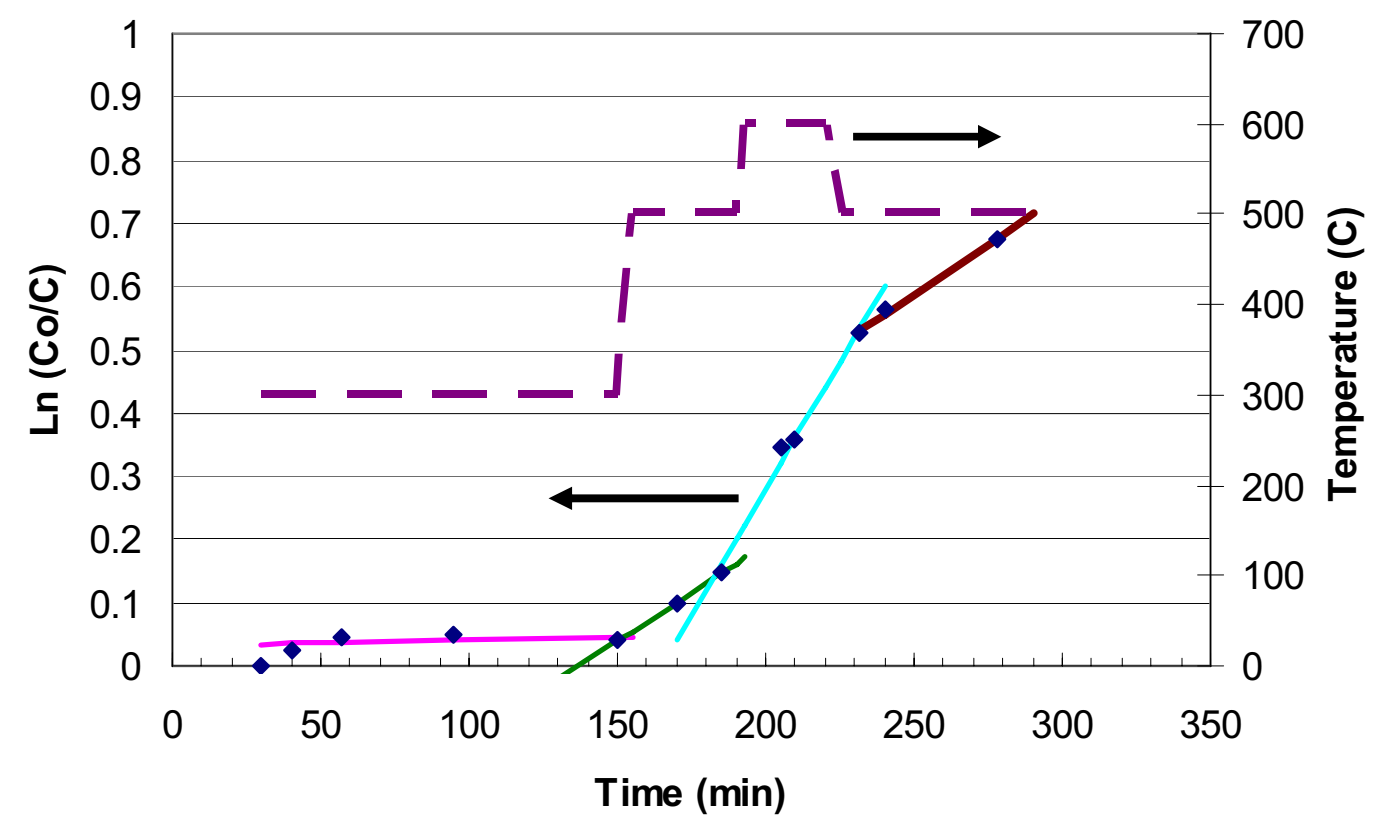

Figure 5. Tritium fraction removed from the experiment of Figure 2.

An Arrhenius Plot of the slopes of the fit lines in Figure 5 appears in Figure 6 . The linearity indicates it is a thermally activated process with an activation energy of $62.84 \mathrm{~kJ} / \mathrm{mole}$. With the assumption that conversion to HTO is a surface process whose rate will depend on the surfaceto-volume ratio, the fraction of HT not converted follows the relation 


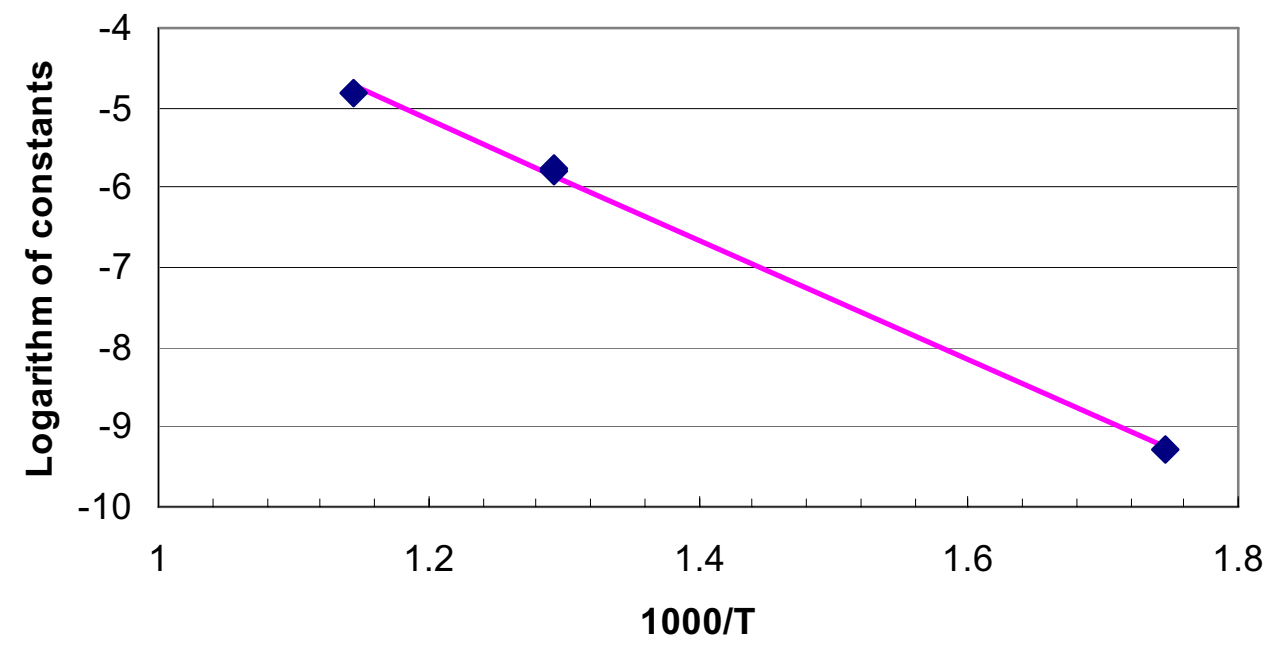

Figure 6. Arrhenius plot of slopes of oxidation rates in Figure 5.

$$
\frac{C}{C_{o}}=\exp \left[-1.987 S \exp \left(-\frac{62,840}{R T}\right) t\right]
$$

where $\mathrm{C}\left(\mathrm{m}^{-3}\right)$ is the non-condensable or elemental tritium concentration, $\mathrm{C}_{\mathrm{o}}\left(\mathrm{m}^{-3}\right)$ is its initial value, $\mathrm{S}\left(\mathrm{m}^{-1}\right)$ is the surface to volume ratio for the system, $\mathrm{R}$ is the universal gas constant $(\mathrm{J} / \mathrm{mole}-\mathrm{K}), \mathrm{T}$ is the temperature $(\mathrm{K})$, and time is measured in minutes.

In the experimental data shown, the water vapor adsorbed on the system surface may have reached saturation or at least equilibrium relatively quickly. Shiraishi et al. [1] found that water adsorption $q\left(\mathrm{~mol} / \mathrm{m}^{2}\right)$ on a Type 304 stainless steel surface was insensitive to temperature but was dependent on water vapor pressure $P(\mathrm{~Pa})$ through the relation

$$
q\left(\frac{m o l}{m^{2}}\right)=6.04 \times 10^{-6} P^{2 / 3}
$$

over the range of about 10 to $200 \mathrm{~Pa}$. This should apply to all isotopic forms (isotopomers) of water collectively. From the cold-trap-on condensable tritium readings $\left(3 \mathrm{mCi} / \mathrm{m}^{3}\right)$ during the initial equilibrium in Figure 2, the HTO partial pressure was about $260 \mu \mathrm{Pa}$ with 2.94E-10 moles of HTO in the vapor phase. From the amount of tritium lost from the inner loop $\left(1 \mathrm{mCi} / \mathrm{m}^{3}, 9.6 \mathrm{E}-\right.$ 11 moles, presumably from conversion and adsorption), the average areal density of HTO coming from the gas on the inner loop walls would have been about $1.26 \mathrm{E}-10 \mathrm{~mole} / \mathrm{m}^{2}$ or about 4E-06 molecules per surface lattice site. That is far lower than the $2.46 \mathrm{E}-8 \mathrm{~mole} / \mathrm{m}^{2}$ predicted by Eq. (2) for the evident HTO vapor pressure of $260 \mu \mathrm{Pa}$ alone. If Eq. (1) applies collectively to all water isotopomers and extends to much lower pressures than $10 \mathrm{~Pa}$, and if it is assumed that $\mathrm{P}_{\mathrm{HTO}}$ $=260 \mu \mathrm{Pa}$ and $\mathrm{P}_{\mathrm{H} 2 \mathrm{O}}=1 \mathrm{~Pa}$ (the $\mathrm{H}_{2} / \mathrm{HT}$ ratio was about 3400 ), Eq. (2) would give a total wall inventory of $5.56 \mathrm{E}-06 \mathrm{~mole} / \mathrm{m}^{2}$ of which the HTO inventory would be about $1.64 \mathrm{e}-09 \mathrm{~mole} / \mathrm{m}^{2}$. This is an order of magnitude greater than that apparent from the tritium lost from the inner loop gas phase. Thus it must be assumed that either the amount of HTO estimated from the experimental data to be on the surface was incorrect, or that other processes are active. 
It is possible that there was considerable residual water on the surface that was not released under the evacuation procedures used at the start of the test. That is consistent with the observation of Nishikawa et al. [2] that dry gas, even with hydrogen included, is not effective in removing all the tritiated water from stainless steel surfaces. Some surface water remains bound to the surface.

In the study of Nishikawa et al. [2] of isotopic exchange on surfaces, they found the saturation value of $\mathrm{T}_{2} \mathrm{O}$ on $304 \mathrm{SS}$ to be temperature dependent but independent of pressure. For $\mathrm{T}_{2} \mathrm{O}$ pressures less than $370 \mathrm{~Pa}$, they found the saturation loading in isotopic exchange to be $\mathrm{a}^{\mathrm{a}}$

$$
\begin{array}{ll}
\mathrm{Q}\left(\mathrm{Ci} / \mathrm{m}^{2}\right)=12.6 \mathrm{Tg} / \mathrm{Hg} \exp (730 / \mathrm{RT}) & \mathrm{T}<100^{\circ} \mathrm{C} \\
\mathrm{Q}\left(\mathrm{Ci} / \mathrm{m}^{2}\right)=0.447 \mathrm{Tg} / \mathrm{Hg} \exp (3200 / \mathrm{RT}) & \mathrm{T}>100^{\circ} \mathrm{C}
\end{array}
$$

In the experiment of Figure 2 with $\mathrm{T}_{\mathrm{g}} / \mathrm{H}_{\mathrm{g}}$ of about $2.4 \mathrm{E}-04$ and initial temperature of $23^{\circ} \mathrm{C}$ $(300 \mathrm{~K})$, Eq. (3) gives a surface layer saturation of $4.96 \mathrm{mCi} / \mathrm{m}^{2}$. The loss of $3 \%$ of the initial tritium while the experiment of Figure 2 was still at room temperature suggests that $2.47 \mathrm{mCi} / \mathrm{m}^{2}$ was lost to the walls during the initial stages of that experiment. The partial pressure of HTO was relatively constant during that time, indicating that HTO was not moving to the walls then, so there may have been a previous inventory on the walls to cause them to be saturated if Eq. (3) is assumed to hold.

As permeation column temperature increased, the amount of HTO lost from the gas phase increased. That change is in the opposite direction to that predicted by Eqs. (3) and (4) if saturation had been achieved at lower temperatures. Further, the loss did not decrease as temperature dropped from $600^{\circ} \mathrm{C}$ to $500^{\circ} \mathrm{C}$. However, this effect is probably due to the deposition in cooler regions of HTO released from the hotter regions.

A further telling point is the overshoot or spikes that appear in total tritium concentration in the inner loop when the $\mathrm{LN}_{2}$ is removed. In every case, the tritium concentration rises momentarily and then relaxes to a previous equilibrium as tritium, presumably as HTO, moves from the gas phase to the surface. Hence, there is some pressure sensitivity to the amount of HTO on the surfaces. One must then conclude that Eqs. (3) and (4) do not entirely govern in this situation. It appears that some adsorption is going on as well as isotopic replacement.

In the second experiment, the time constant for loss of non-condensable tritium between 45 and 150 minutes was 70 minutes. Again note that when the $\mathrm{LN}_{2}$ was removed from the inner-loop cold trap, there was an adjustment period of from 6 to 10 minutes while the total tritium in the system came to a new equilibrium. Once again, the loss rate of tritium from the inner loop increased when permeation column temperature was increased from 500 to $600^{\circ} \mathrm{C}$, but the amount lost cannot be accounted for by permeation into the outer loop or uptake in the tube wall.

\footnotetext{
${ }^{\text {a }}$ Note that Nishikawa et al. used $1.986 \mathrm{cal} /$ gmole-K for $\mathrm{R}$, not $8.314 \mathrm{~J} /$ gmole-K used elsewhere in this report.
} 
Perhaps the most striking feature of the second experiment is the clear demonstration in the post 200-minute time frame that HTO contributed substantially and directly to permeation. The rate of increase of tritium in the outer loop clearly accelerated when the temperature was increased to $600^{\circ} \mathrm{C}$, but when $\mathrm{LN}_{2}$ was applied to the inner loop cold trap, the rate decreased in direct proportion to the fraction of tritium frozen out as HTO. It returned to its previous rate, or even a little higher rate when the $\mathrm{LN}_{2}$ was removed. From the shape of the outer loop tritium activity history while the $\mathrm{LN}_{2}$ was applied to it in the time from 240 to 252 minutes, it is clear that the HTO fraction in the outer loop was increasing in time. This implies that conversion of HT to HTO in the outer loop did not take place as the tritium came through the diffusion column, but took place later and possibly elsewhere.

Turning now to the third experiment, shown in Figure 4, when the tritium was admitted to the column, after sitting in the loop overnight, the gaseous tritium activity had fallen to only about $11 \mathrm{mCi} / \mathrm{m}^{3}$ from its initial $20 \mathrm{mCi} / \mathrm{m}^{3}$. This appears due to the conversion of HT to HTO and its adsorption or exchange on the surface-bound water or $\mathrm{OH}$. The time constant for conversion of HT to HTO in the first 160 minutes of the experiment was observed to range from about 75 minutes to 550 minutes with the average being about 350 minutes. The time constant from Eq. (1) at $773 \mathrm{~K}$ and $S=272 \mathrm{~m}^{-1}$ is 346 minutes. The agreement is good. The faster rate at the beginning and the slower rate and eventual stopping at the end of the initial conversion period ( $<200$ minutes) suggest the conversion process was moving towards an equilibrium over time. It is worth noting that the period of constancy in the inner loop corresponded with the period when $\mathrm{LN}_{2}$ was applied to the outer loop.

The mass transfer coefficient for loss of water vapor from the gas to adsorption is given by Shiraishi et al. ${ }^{1}$ as

$$
K_{f}\left(\frac{m}{s}\right)=1.49 \times 10^{-3} \exp \left(-\frac{291}{T(K)}\right)
$$

One thus expects that for adsorption

$$
\frac{d c}{d t}=-S K_{f}\left(c-c^{*}\right)
$$

where $c$ is the concentration of HTO in the gas and $c^{*}$ is that concentration that would be in equilibrium with the inventory, $q$, of HTO adsorbed on the surface, and $S$ is again the surface-tovolume ratio for the system. To the degree that $c^{*}$ is constant or varies slowly, Eq. (6) may be rewritten as

$$
\frac{d\left(c-c^{*}\right)}{\left(c-c^{*}\right)}=-S K_{f} d t
$$

for which the time constant is $\left(\mathrm{S} \mathrm{K}_{\mathrm{f}}\right)^{-1}$. For this system at ambient temperature where adsorption was taking place, the time constant from this formula is only 6.5 seconds. This is much shorter than the mixing time constant from pumped circulation in the inner loop of about 40 seconds.

In reality, $c^{*}$ is not constant. It is found from Eq. (2) as a function of wall inventory $q$ and temperature $T$ as 


$$
C^{*}=\frac{p^{*}}{k T}=\frac{1}{k T}\left[1.65 \times 10^{5} q\right]^{3 / 2}
$$

where $k$ is the Boltzmann constant.

The continuity equation for wall inventory is

$$
\frac{d q}{d t}\left(\frac{m o l e}{m^{2} s}\right)=\frac{K_{f}\left(c-c^{*}\right)}{N_{A}}
$$

where $N_{A}$ is Avogadro's number. Substituting for $c^{*}$ using Eq. (8) and supposing from continuity of water vapor in the gas (no source) that

$$
c=c_{o}-\operatorname{SkTN}_{A} q
$$

gives

$$
\frac{d q}{d t}\left(\frac{m o l e}{m^{2} s}\right)=\frac{K_{f} c_{o}}{N_{A}}-S_{k T K} q-6.74 \times 10^{7} \frac{K_{f}}{N_{A} k T} q^{3 / 2}
$$

This non-linear differential equation can be linearized by factoring $q^{3 / 2}$ into two parts, one variable and one pseudo constant, $q \times \bar{q}^{1 / 2}$. Then Eq. (10) can be rewritten as

$$
\frac{d q}{d t}+\left(\operatorname{SkTK}_{f}+6.74 \times 10^{7} \frac{K_{f}}{N_{A} k T} \bar{q}^{1 / 2}\right) q=\frac{K_{f} C}{N_{A}} .
$$

This is an inhomogeneous first order differential equation for which the solution of the corresponding homogeneous equation is

$$
q=q_{o} \exp \left[-\left(S k T K_{f}+6.74 \times 10^{7} \frac{K_{f}}{N_{A} k T} \bar{q}^{1 / 2}\right) t\right]
$$

The time constant for Eq. (12) is

$$
\tau=\left(\operatorname{SkTK} K_{f}+6.74 \times 10^{7} \frac{K_{f}}{N_{A} k T} \bar{q}^{1 / 2}\right)^{-1}
$$

Clearly this time constant changes as $\bar{q}$ increases or decreases. If $\bar{q}$ is varied from $10^{-11}$ to $10^{-8}$ and the average temperature where absorption was taking place is in the range of $300 \mathrm{~K}$ to $600 \mathrm{~K}$ (recall that the column was at $773 \mathrm{~K}$ while the remainder of the loop was about $300 \mathrm{~K}$ ), the time constant is found to vary as shown in Figure 7. The time constants thus calculated are about the same magnitude as those seen in Figure 4. However, Figure 6 shows the time constant decreasing as wall water inventory builds. That is the opposite trend to that manifest Figure 3 where the time constant increases as the wall appears to become more loaded with water. It must be remembered that Eqs. (10) to (13) do not account for a replenishment of the gas-phase vapor by oxidation of HT. 


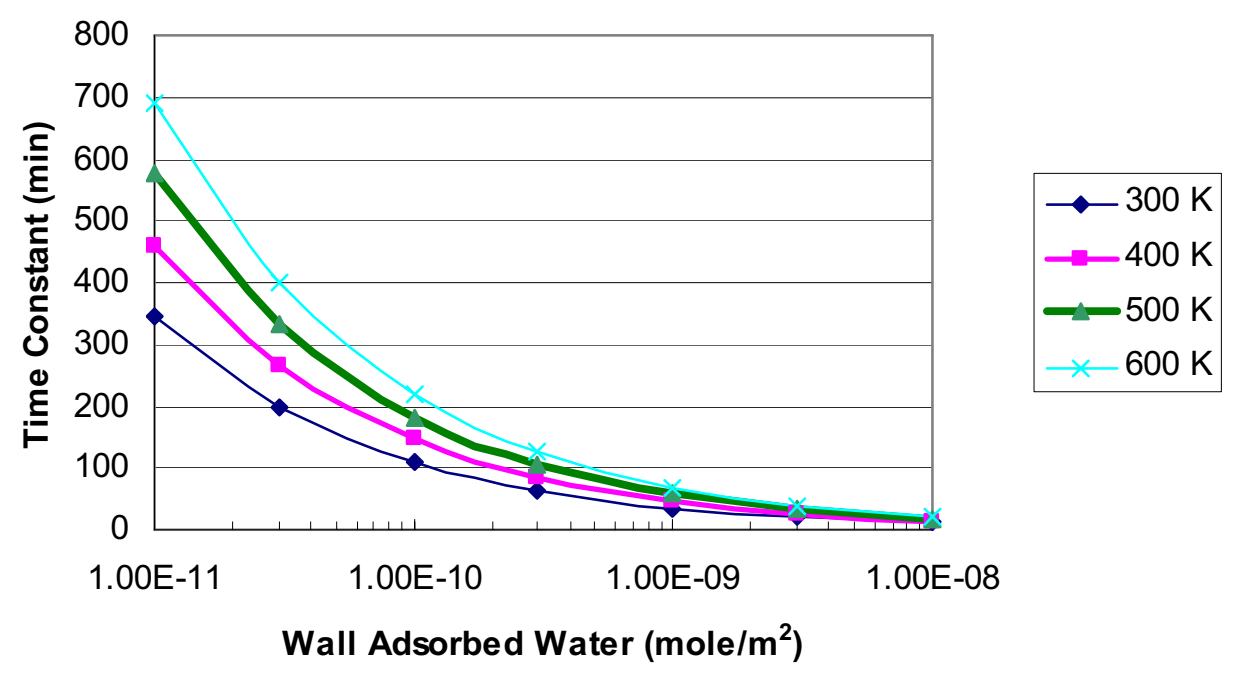

Figure 7. Variation of water adsorption time constant with amount adsorbed.

One is thus left with the suspicion that the conversion rate of HT to HTO described by Eq. (1) is really governed by mass transfer to and from the surface, which is the rate limiting step in loss of tritium from the gas in these experiments.

Permeation during the first 140 minutes of the third experiment was active and declined slightly as the gas phase tritium activity dropped. As is clearly evident, about $90 \%$ of the permeated tritium that remained in the gas phase was present as HTO. Once again note that when the HTO was frozen out of the inner loop, comprising most of the gas-phase tritium, permeation through the column to the outer loop stopped.

It is interesting that when the $\mathrm{LN}_{2}$ was removed from the outer loop at 208 minutes, the tritium activity did not return to a value on the extension of the previous line as it appeared to do towards the end of the experiment in Figure 3. Instead, it recovered to an activity measurably less, suggesting either a reduction in the permeation rate while the $\mathrm{LN}_{2}$ was on the outer loop or that some of the HTO that was frozen out by the $\mathrm{LN}_{2}$ did not return to the gas phase. It appears that there was a time lag of about 20 minutes for permeation to resume after readmitting the HTO driving potential at 260 minutes.

\subsection{CONCLUSIONS}

These experiments illustrate clearly that tritium from HTO permeates the hot stainless steel column readily, with the column at elevated temperatures $\left(>500^{\circ} \mathrm{C}\right)$. A most probable mechanism is molecular dissociation on the hot metal oxide surface with attendant permeation of the single $\mathrm{T}$ atom. That would leave the $\mathrm{OH}$ (or OT) radical on the surface, which could also dissociate or eventually capture a free $\mathrm{H}$ or $\mathrm{T}$ or even form peroxide with another radical and move to a colder surface. 
It is also apparent that the movement of water to and from the surfaces was the rate controlling step in the process of conversion of HT to HTO in these experiments. The rate of such conversion was found to be consistent with that given by Eq. (1).

One may conclude further that both adsorption of molecular water on the surface and isotopic exchange of tritium with surface-bound water were taking place during these experiments.

\section{Disclaimer}

References to commercial products or brand names does not constitute endorsement of those products.

\section{References}

1. T. Shiraishi et al., July 1977, "Adsorption and Desorption Behavior of Tritiated Water on the Piping Materials," Journal of Nuclear Science and Technology, 34, No. 7, pp. 687 - 694.

2. M. Nishikawa et al., March 1992, "Tritium Mass Balance in the Piping System of a Fusion Reactor,” Fusion Technology, 21, pp. 878 - 882. 